\title{
Fluorine Speciation in Loess in The Shaanxi Loess Plateau, Related Quality Assessment And Exposure Risks Implication
}

Lin Deng ( $\sim$ deng_lin@chd.edu.cn )

Chang'an University https://orcid.org/0000-0002-2460-9449

Jiangxia Wang

Chang'an University

Bin Xu

Chang'an University

Xiaoting Yang

Chang'an University

Anyan $\mathrm{Hu}$

Chang'an University

\section{Research Article}

Keywords: Fluorine speciation, Loess, Exposure, Risk, High-fluoride groundwater

Posted Date: November 9th, 2021

DOI: https://doi.org/10.21203/rs.3.rs-1032899/v1

License: (9) This work is licensed under a Creative Commons Attribution 4.0 International License.

Read Full License 
Fluorine speciation in loess in the Shaanxi Loess Plateau, related quality assessment and exposure risks implication ${ }^{*}$ Lin Deng ${ }^{1,2},{ }^{*}$ Jiangxia Wang ${ }^{1,2}$, Bin Xu ${ }^{1,2}$, Xiaoting Yang ${ }^{1,2}$, Anyan $\mathrm{Hu}^{1,2}$

${ }^{1}$ School of Water and Environment, Chang' an University, Xi'an, Shaanxi, China; ${ }^{2}$ Key Laboratory of Subsurface Hydrology and Ecological Effects in Arid Region, Ministry of Education, Chang'an University, Xi'an, Shaanxi, China

${ }^{*}$ Corresponding author

\section{Abstract}

In this study, distributing characteristics of five fluorine (F) species in loess in the Shaanxi Loess Plateau (SLP) were determined including unextractable residual $\mathrm{F}\left(\mathrm{F}_{\mathrm{re}}\right)$, extractable water-soluble $\mathrm{F}$ $\left(F_{w s}\right)$, exchangeable $F\left(F_{e x}\right)$, F bound to Fe-Mn oxides $\left(F_{f m}\right)$, and $F$ bound to organics $\left(F_{o r}\right)$. The results show that unextractable $\mathrm{F}_{\mathrm{re}}$ represents most percentage of $\mathrm{F}_{\mathrm{tf}}$ in loess. Of the four extractable F species, the content of $F_{w s}$ is higher than the other three extractable $F$ species in most loess samples. The loess in the southeast SLP has the highest $\mathrm{F}_{\mathrm{ws}}$ content while the loess in the southwest has the highest $\mathrm{F}_{\mathrm{tf}}$ content. And the loess in the north SLP contains the lowest overall concentrations of $\mathrm{F}_{\mathrm{tf}}$ and $F_{w s}$. Similar to $F_{w s}$, the respective content of $F_{e x}, F_{f m}$, and $F_{\text {or }}$ in the loess is also very low. However, the total of them and $\mathrm{F}_{\mathrm{ws}}$ cannot be negligible for $\mathrm{F}$ mobility in loess. Overall, the loess in the SLP can be assessed as inferior quality in terms of $\mathrm{F}$ as a result of high $\mathrm{F}_{\mathrm{ws}}$ content in most samples. Based on the F speciation in the loess, F exposure to grazing animals and humans, in fact to children, was assessed, indicating that F in the loess in the southwest SLP might pose a much greater risk to grazing animals than in other part of SLP as the loess contains more $\mathrm{F}_{\mathrm{tf}}$. However, there is no concern for the children's exposure to loess F via ingestion in the study area in the present condition. As for the loess $\mathrm{F}$ risk to groundwater, it can be concluded that not only $\mathrm{F}_{\mathrm{ws}}$ but also the other extractable $\mathrm{F}$ including $\mathrm{F}_{\mathrm{ex}}, \mathrm{F}_{\mathrm{fm}}$ and $\mathrm{F}_{\text {or }}$ in loess may be responsible for the $\mathrm{F}$ enrichment in local groundwater in the area with the aid of the characteristics of $\mathrm{F}$ speciation in loess and distribution of local high-fluoride groundwater.

Key words: Fluorine speciation; Loess; Exposure; Risk; High-fluoride groundwater

\section{Introduction}

Fluorine (F) is a critical element for animals and humans, particularly for the development of bones and dental enamel (Loganathan et al. 2006; Jha et al. 2011; WHO, 2017). It has a beneficial effect on health only if the F intake amount is not in excess of the limit dose. Otherwise, harmful effects 
would have on animals and humans like dental and skeletal fluorosis (Fewtrell et al. 2006). Soils are a source of F for the biosphere (Davison and Weinstein 2006). Highly enriched F in soils may constitute potential risks for animals and humans. For animals, previous studies showed that grazing animals were faced with potential fluorosis due to large rates of ingestion of high-fluorine soil (Cronin et al. 2000; McLaughlin et al. 2001). In this case, total $\mathrm{F}\left(\mathrm{F}_{\mathrm{tf}}\right)$ content in soils was considered responsible for the fluorosis risk to grazing animals (Loganathan et al. 2006). On the other hand, for humans, soil intake may also cause potential exposure risks to environmental contaminants, particularly for young children sometimes with up to 10 times more soil ingested than adults, per kilogram body weight (Egeghy et al. 2007). To evaluate whether high-F soils would pose direct potential risk to humans, it is not enough just to determine $\mathrm{F}_{\mathrm{ff}}$ content in soil. This is because exposure to contaminants via ingestion of soil also depends on combined ingestion rate of soil, and relative oral bioavailability in the human body for contaminants in soil besides their content (Bierkens et al. 2011). The relative oral bioavailability of $\mathrm{F}$ in the human body is governed by many factors and hard to assessed. In comparison, water-soluble fluorine $\left(\mathrm{F}_{\mathrm{ws}}\right)$ in soils may be more easily determined and it is bioaccessible $\mathrm{F}$ in a labile form, which closely reflects the mobility of soil $\mathrm{F}$ (Xie et al. 1999; Cronin et al. 2000; Loganathan et al. 2006; Yi et al. 2013). Therefore, it is reasonable and feasible that $\mathrm{F}_{\mathrm{ws}}$ is used in the assessment of human's exposure to soil $\mathrm{F}$. In addition, F enrichment in groundwaters was generally attributed to geogenic F (D'Alessandro et al. 2008; Borgnino et al. 2013; Li et al. 2014; Brindha et al. 2016; Fuge 2019). Fluorine-bearing minerals in rocks and soils are the most important geogenic source of fluoride enrichment in groundwater (Ayenew 2008; D’Alessandro et al. 2008; Arveti et al. 2011; Andrade 2012). Under some conditions, $\mathrm{F}$ in soils is prone to migrate to groundwater and available to plants and hence constitute risks of F-elevation to groundwater and F-toxicity risks to plants (Cronin et al. 2000; Loganathan et al. 2006; Yi et al. 2013). However, it was reported that F-contamination risk to groundwater depends on the soluble soil $\mathrm{F}$ concentrations instead of $\mathrm{F}_{\mathrm{tf}}$ in soil. In other words, the presence of soluble and/or labile fluoride in soils is the major controlling factor for the fluoride levels in groundwater (Loganathan et al. 2006; Jayawardana et al. 2012). Since comprehensive studies on the geochemistry of $\mathrm{F}$ in soils are still generally lacking, there are only limited studies focused on soluble F concentrations or fluorine speciation in soils in spite of the large number of studies on $\mathrm{F}_{\mathrm{tf}}$ concentrations (Berger et al. 2016). Therefore, research on $\mathrm{F}$ speciation may help 
elucidate labile forms of soil $\mathrm{F}$ and aid in profound studies on geochemistry of $\mathrm{F}$ in soils. Moreover, the relationship between soil F speciation and groundwater F content will be helpful in better understanding genesis of groundwater $\mathrm{F}$, which is important to formation mechanisms of local highfluoride groundwater.

Loess is widely distributed in China with its typical ang deep sediments in the Chinese Loess Plateau (CLP). People in the CLP heavily rely on groundwater for daily life, whereas groundwater quality there is usually not qualified enough due to excessive salinity and some toxic elements ( $\mathrm{Li}$ et al. 2019). F is one of such toxic elements (Zhu et al. 2006; Currell et al. 2011). Particularly in the Shaanxi Loess Plateau (SLP), which is the core area of the CLP and within the scope of Shaaxi Province, high-F groundwater has long been a major hydrogeological issue. Geologic F was found to be the origin of fluoride in the groundwater in the area (Zhu et al. 2008; Deng et al. 2009b; Li et al. 2019). As loess is an important source of fluorine in the groundwater, $F_{t f}$ in basic loess units has been evaluated in some regions in the SLP with limited $F_{w s}$ records obtained (Liu, 1985; Zhu et al. 2008; Liu et al. 2009). Previous analyses show that $\mathrm{F}$ content in loess ranges from $74-653 \mathrm{mg} \mathrm{kg}^{-1}$ while $\mathrm{F}_{\mathrm{ws}}$ content is between 1.75 and $38 \mathrm{mg} \mathrm{kg}^{-1}$ (Liu et al. 2009). Nevertheless, information on labile forms of $\mathrm{F}$ in loess is still far from enough as there are few studies on $\mathrm{F}$ speciation in loess. Much less is the exposure and risk implication related to labile forms of $\mathrm{F}$ in loess. Therefore, this study aims to: (1) determine characteristics of the F speciation in loess in the SLP; (2) assess the quality of the loess in the area in terms of F based on the F speciation; (3) disclose the exposure and risk implications of $\mathrm{F}$ in loess associated with the $\mathrm{F}$ speciation, including that to animals, humans and groundwater. This study may enhance the understanding of F geochemistry in loess, improve knowledge on animal and human health protection related to $\mathrm{F}$ in the area and afford further information on genesis of high-fluoride groundwater in the SLP.

\section{Regional setting}

The SLP is located in the central of the CLP with widely distributed thick loess accumulations. It is generally agreed that loess is an accumulation of wind-borne dust and silt derived from deflation of surface rocks in arid areas with severe winters to the north and west of the main loess belt. The mineralogy of loess is mainly composed of quartz, feldspar and muscovite and such clay minerals like illite, kaolinite and montmorillonite (Liu et al. 1986). There is a northwest and southeast 
progression in spatial domain of loess from sandy loess to silty loess, and to fine loess, all of which are distinguished from one another in their physical and chemical characteristics. At the same time, vertically in a profile, loess is composed of alternating loess and paleosols with totally four basic units being recognized if the stratigraphy is complete, including Holocene Loess, Upper Pleistocene Malan Loess, Middle Pleistocene Lishi Loess, and Lower Pleistocene Wucheng Loess. As their alternation resulted from shifting climatic regimes, loess and paleosols displays distinct characteristics in physical and geochemical compositions (Liu, 1985).

The SLP has a typically arid and semiarid climate. Water resources in the area are rather limited due to limited precipitation and continuous increasing of water demand. As surface water resource is unevenly distributed and inadequate, groundwater there play an important role in water supply for various purposes. However, high-fluoride groundwater occurs widely across the area (Li et al. 2019). In some localities in the SLP, the endemic fluorosis was attributed to excessive intake of fluoride via drinking high-fluoride shallow groundwater (Zhu et al. 2008). It is the case in the Guanzhong Basin located in the southern SLP, particularly in the east of the basin (Deng et al. 2009b).

\section{Materials and methods}

Sampling and analyzing

Four loess profiles in the SLP were chosen for sampling in this study, as shown in Fig 1. They are named Luochuan (LC) profile, Baoji (BJ) profile, Bailuyuan (BLY) profile and Dali (DL) profile, respectively. The LC profile is located in Luochuan County in the north of the SLP with typical loess (silty loess) distributed and the latter three in the south with fine loess distributed. And the latter three profiles lie in the north of Baoji City, the southeast of Xi'an City, and the north of Dali County, respectively. On the regional scale, they are also in the southwest, south-central and southeast of the SLP, respectively. All the profiles are composed of alternating loess and paleosol sequences. Totally 60 loess and paleosol samples were collected from the four profiles. Among them 11 were sampled from the LC profile, 16 from the BJ profile, 15 from BLY profile, and 18 from Dali profile. One or two samples were taken from each layer of loess or paleosol in the profiles.

Fig 1

Samples were first air dried. Then they were sieved through a 2-mm mesh and completely mixed. Soil $\mathrm{pH}$ was measured in deionized water with a soil/solution weight ratio of $1 / 2.5 \mathrm{using}$ a pH meter. 
Total $\mathrm{F}\left(\mathrm{F}_{\mathrm{tf}}\right)$ content of the samples was analyzed using alkali fusion-selective electrode technique (D'Alessandro et al. 2008). A sequential chemical extraction (SCE) procedure was followed to obtain fluorine speciation in detail (Wu et al. 2002; Yi et al. 2013). Five grams of the sieved samples were put into a 50-ml centrifuge tube. First, water-soluble $\mathrm{F}\left(\mathrm{F}_{\mathrm{ws}}\right)$ was leached by deionized water at about $70^{\circ} \mathrm{C}$ after continuously shaking for 1 hour. The centrifuged leach solution was for determination of $\mathrm{F}_{\mathrm{ws}}$. Then the remnant was used to extract exchangeable $\mathrm{F}\left(\mathrm{F}_{\mathrm{ex}}\right)$ by adding $1 \mathrm{~mol}$ $\mathrm{L}^{-1} \mathrm{MgCl}$ solution $(\mathrm{pH}=7.0)$ and shaking for 1 hour at room temperature. The supernatant after centrifugation was kept for $\mathrm{F}_{\mathrm{ex}}$ determination while the remnant was mixed with $0.04 \mathrm{~mol} \mathrm{~L}^{-1}$ $\mathrm{NH}_{2} \mathrm{OH} \cdot \mathrm{HCl}$ dissolved in $20 \%$ (in volume) $\mathrm{CH}_{3} \mathrm{COOH}$ solution and shaken for 1 hour at $60^{\circ} \mathrm{C}$ to extract $\mathrm{F}$ bound to $\mathrm{Fe}-\mathrm{Mn}$ oxides $\left(\mathrm{F}_{\mathrm{fm}}\right)$. Subsequently, the mixture with the extracted $\mathrm{F}_{\mathrm{fm}}$ was centrifuged and the supernatant and remnant were for content analysis of $\mathrm{F}_{\mathrm{fm}}$ and extraction of $\mathrm{F}$ bound to organics $\left(\mathrm{F}_{\mathrm{or}}\right)$, respectively. The remnant from the last step was treated with $0.02 \mathrm{~mol} \mathrm{~L}^{-1}$ $\mathrm{HNO}_{3}$ and $30 \% \mathrm{H}_{2} \mathrm{O}_{2}$ and then $3.2 \mathrm{~mol} \mathrm{~L}^{-1} \mathrm{NH}_{4} \mathrm{Ac}$ was added. After that, 1-hour shaking was conducted to complete extraction of $F_{\text {or }}$. Suspension was then centrifuged for $F_{\text {or }}$ analysis. The supernatant in each step was mixed with TISAB before running on a F ion-selective electrode for F concentration. The detection limit is $1 \mathrm{mg} \mathrm{kg}^{-1}$ and the precision is $\pm 10 \%$. Residual $\mathrm{F}$ content $\left(\mathrm{F}_{\mathrm{re}}\right)$ was obtained by a remaining difference method, namely $\mathrm{F}_{\mathrm{tf}}$ minus the sum of the above four species of $F$.

\section{Methods}

Quality assessment with respect to F

In this study, the method introduced by Li et al. (2005) was applied to assess the quality of loess in terms of F. It was established based on statistical relationship between geochemical characteristics of $\mathrm{F}$ in high-fluorine soils and local occurrences of endemic fluorosis in China. The assessment is made according to the formula as follows: where $C_{i}\left(\mathrm{mg} \mathrm{kg}^{-1}\right)$ is the analyzed concentration of F in soil; $S_{1}$ and $S_{2}\left(\mathrm{mg} \mathrm{kg}^{-1}\right)$ are the lower and upper limits of standard concentrations of $\mathrm{F}$ for the assessment, respectively. The values for $C_{i}, S_{1}$ and $S_{2}$ are taken differently according to $\mathrm{pH}$ of soil. If soil $\mathrm{pH}$ is acid 
$154(\mathrm{pH}<7), \mathrm{F}_{\mathrm{tf}}$ concentration in the soil is adopted as $C_{i} . S_{1}$ is the world average $\mathrm{F}_{\mathrm{tf}}$ content in soil 155 and $S_{2}$ is the average $\mathrm{F}_{\mathrm{tf}}$ content in soil in areas in China where endemic fluorosis highly occurs. 156 The values of $S_{1}$ and $S_{2}$ are 200 and $800 \mathrm{mg} \mathrm{kg}^{-1}$, respectively (Li et al. 2005; Wang et al. 2012). 157 If soil $\mathrm{pH}$ is alkaline $(\mathrm{pH}>7)$, however, the measured $\mathrm{F}_{\mathrm{ws}}$ concentration in the soil is taken as $C_{i} . S_{1}$ 158 denotes average $F_{w s}$ content in worldwide uncontaminated surface soils and its value is $0.5 \mathrm{mg} \mathrm{kg}^{-1}$ 159 (CNEMC, 1990). $S_{2}$ is the counterpart in soils in fluorosis prevalence areas of China and generally 160 has the value of $2.5 \mathrm{mg} \mathrm{kg}^{-1}$ according to the statistics from Li et al. (2005). But herein $5.0 \mathrm{mg} \mathrm{kg}^{-1}$ 161 is taken as the value of $S_{2}$ under the alkaline condition in accordance with the limit in quality standard for agricultural land stipulated by GB15618-2018 (MEE, 2018).

163 To make a quantitative comparison, a soil health quality index for fluorine ( $\left.P_{i}\right)$ was also 164 introduced by Li et al. (2005):

$$
P_{i}=\frac{C_{i}}{S_{2}}
$$

where $C_{i}$ and $S_{2}$ are the same as those in formula (1). Similar to formula (1), $P_{i}>1$ indicates that the evaluated soil is high-fluorine and its health quality associated with $\mathrm{F}$ is inferior. And the larger the $P_{i}$, the worse the soil health quality of $\mathrm{F}$.

\section{Exposure risks assessment}

Daily exposure to soil F (DF) is assessed for grazing animals according to whether acceptable limits of dietary F for grazing animals are surpassed. If DM $(\mathrm{kg})$ is the daily dry matter intake by a certain grazing animal, a safe threshold dietary concentration for $\mathrm{F}$ is $60 \mathrm{mg} \mathrm{kg}^{-1} \mathrm{DM}$ for breeding ewes and $150 \mathrm{mg} \mathrm{kg}^{-1} \mathrm{DM}$ for lambs. And $10-25 \%$ of DM intake is for the range of daily soil ingestion (RDSI) (Grace et al. 2003). Then the DF on a dietary basis $\left(\mathrm{mg} \mathrm{kg}^{-1}\right)$ by a grazing animal could be evaluated as follows:

$\mathrm{DF}=\frac{D M \times R D S I \times C_{t f}}{D M}=R D S I \times C_{t f}$

where $C_{t f}\left(\mathrm{mg} \mathrm{kg}^{-1}\right)$ is $\mathrm{F}_{\mathrm{tf}}$ content in soils. Human exposure to contaminants through ingestion of soil may be estimated by the following equation (Bierkens et al. 2011):

$$
\mathrm{DI}=\frac{I R_{\text {Soil }} \times F_{\text {soil }} \times R B A_{\text {soil }} \times C_{\text {soil }} \times 10^{-3}}{B W}
$$

182 where DI is exposure through daily intakes of soil $\left(\mu \mathrm{g} \mathrm{kg} \mathrm{kg}^{-1} \mathrm{day}^{-1}\right) ; I R_{\text {soil }}$ is combined ingestion 
rate of soil $\left(\mathrm{mg} \mathrm{day}^{-1}\right)$; dimensionless $F_{\text {soil }}$ is fraction of soil and dust ingestion which is soil; dimensionless $R B A_{\text {soil }}$ is relative oral bioavailability in the human body for contaminants in soil; $C_{\text {soil }}$ is contaminant concentration in soil $\left(\mathrm{mg} \mathrm{kg}^{-1}\right)$; BW is average body weight $(\mathrm{kg})$.

Here children's exposure to $\mathrm{F}$ in loess was assessed as they tend to have much more hand-to mouth activities for soils than adults. In the assessment, a representative value of $50 \mathrm{mg} \mathrm{day}^{-1}$ is for $I R_{\text {soil }}$ (Bierkens et al. 2011). As for $R B A_{\text {soil }}$, its value was not determined alone because of lack of related experiments. Instead, the product of $R B A_{\text {soil }}$ and $C_{\text {soil }}$ was given a value which was considered as the oral bioaccessible F concentration to the human body. Some researchers reported that Ftoxicity risk to plants and humans depended on the soluble soil F concentrations (Gao et al. 1990; Loganathan et al. 2006). Also, Yu et al. (2020) found that there were notable positive influences of $F_{w s}$ on oral bioaccessibility of $F$. Therefore, $F_{w s}$ in loess was treated as the approximation of oral bioaccessible $\mathrm{F}$ concentration of loess and substituted for the product of $R B A_{\text {soil }}$ and $C_{\text {soil }}$ to obtain a maximum DI estimate. The value of $F_{\text {soil }}$ herein is 1 as no dust was considered; $15.9 \mathrm{~kg}$ is the BW for children on the basis of local statistics (Xu et al. 2019). The upper intake F levels (ULs) limit for daily intakes is $58 \mu \mathrm{g} \mathrm{kg}^{-1}$ day $^{-1}$ (Chinese Nutrition Society, 2014).

\section{Results and Discussion}

\section{Distribution characteristics of fluorine speciation in loess}

Statistical results of fluorine speciation for the loess samples are included in Table 1. Fig 2 also aids in recognizing distribution characteristics of F speciation in loess in the SLP.

\section{Table 1}

Total fluorine $\left(\mathrm{F}_{\mathrm{tf}}\right)$

$F_{\text {tf }}$ for all the samples vary from 461.45 to $789.72 \mathrm{mg} \mathrm{kg}^{-1}$, with an average of $595.85 \mathrm{mg} \mathrm{kg}^{-1}$ (Table 1). It was reported that the average $F_{t f}$ concentration in soils in China was $478 \mathrm{mg} \mathrm{kg}^{-1}$ and that in worldwide soils was $329 \mathrm{mg} \mathrm{kg}^{-1}$ (Kabata-Pendias and Pendias, 2001; Yi et al. 2013). The average $\mathrm{F}_{\mathrm{tf}}$ content in the loess is considerably higher than that in nation-wide and world-wide soils. The LC profile in the north has an average $\mathrm{F}_{\mathrm{tf}}$ content of $540.44 \mathrm{mg} \mathrm{kg}^{-1}$, which is the lowest of all the profiles (Fig 2). In the south of SLP, the $\mathrm{F}_{\mathrm{tf}}$ content in loess is higher. And the average $\mathrm{F}_{\mathrm{tf}}$ content for $\mathrm{BJ}, \mathrm{BLY}$, and DL profile in the south is $642.84,587.79$, and $594.67 \mathrm{mg} \mathrm{kg}^{-1}$, respectively, with the highest average $\mathrm{F}_{\mathrm{tf}}$ content in the loess in the southwest and the second highest in the southeast. 
214 Water-soluble fluorine $\left(\mathrm{F}_{\mathrm{ws}}\right)$

$215 \quad F_{w s}$ is the $F$ extracted by neutral deionized water as a solvent and mainly exists in inorganic forms.

216 It has a profound effect on plants, animals, microorganisms, and humans with highly availability to

217 roots and active involvement in F accumulation in the food chain (Xie et al. 1999; Yi et al. 2013).

218 Overall, $\mathrm{F}_{\mathrm{ws}}$ accounts for $0.3-6.4 \%$ of the $\mathrm{F}_{\mathrm{tf}}$ in the loess. The range of its content is $1.40-38.97 \mathrm{mg}$

$219 \mathrm{~kg}^{-1}$ in the all the loess samples, with an average of $6.14 \mathrm{mg} \mathrm{kg}^{-1}$ (Table 1). Average $\mathrm{F}_{\mathrm{ws}}$ content in

220 loess is far above $2.5 \mathrm{mg} \mathrm{kg}^{-1}$, the corresponding average in soils in Chinese endemic fluorosis prone

221 areas (Li et al. 2005; Yi et al. 2013). The $\mathrm{F}_{\mathrm{ws}}$ concentrations in loess are nearly one to two orders of

222 magnitude less than that of the $\mathrm{F}_{\mathrm{tf} .}$ The LC profile in the north has the lowest average $\mathrm{F}_{\mathrm{ws}}$ content.

223 However, the highest average content of $\mathrm{F}_{\mathrm{ws}}$ occurs in the DL profile in the southeast that has the

224 second highest $\mathrm{F}_{\mathrm{tf}}$ content (Fig 2). In this profile, the $\mathrm{F}_{\mathrm{ws}}$ represents about $4.1 \%$ of the $\mathrm{F}_{\mathrm{tf}}$ on average,

225 which is much higher than that in the other three profiles. The BJ profile in the southwest has the

226 second highest $\mathrm{F}_{\mathrm{ws}}$ content in spite of $\mathrm{F}_{\mathrm{tf}}$ in it enriched to the greatest extent (Fig 2).

227 Exchangeable fluorine $\left(\mathrm{F}_{\mathrm{ex}}\right)$

$228 \quad \mathrm{~F}_{\mathrm{ex}}$ is the fluoride held by electrostatic attraction and adsorbed on positively charged clay, organic 229 particles and hydrated oxides (Xie et al. 1999). The average $F_{\mathrm{ex}}$ content in all the loess samples is 230 only $11.94 \mathrm{mg} \mathrm{kg}^{-1}$ although its fluctuation range is between 1.31 and $64.20 \mathrm{mg} \mathrm{kg}^{-1}$ much wider 231 than that of $F_{w s}$ (Table 1). As a matter of fact, most of the loess samples have lower $F_{e x}$ content 232 compared to that of $F_{w s}$ (Fig 2). Particularly, average content of $F_{e x}$ in the three profiles in the south 233 is smaller than that of $F_{w s}$. As shown in Fig 2, the LC profile in the north is the only one enriched 234 more $\mathrm{F}_{\mathrm{ex}}$ than $\mathrm{F}_{\mathrm{ws}}$. Nevertheless, the DL profile in the southeast has the highest average $\mathrm{F}_{\mathrm{ex}}$ content 235 as well as the highest that of $F_{w s}$. Similar to the ranking in terms of average $F_{w s}$ content in the profile, 236 it is followed by the BJ profile in the southwest, the BLY profile in the south-central SLP, and the 237 LC profile in the north according to the average $F_{\mathrm{ex}}$ content of the respective profile (Fig 2).

238 Fluorine bound to Fe-Mn oxides $\left(\mathrm{F}_{\mathrm{fm}}\right)$

$239 \mathrm{~F}_{\mathrm{fm}}$ actually refers to the part of $\mathrm{F}$ in soils that may be absorbed by $\mathrm{Fe}, \mathrm{Mn}$ and $\mathrm{Al}$ oxides, 240 oxyhydroxides, and hydrated oxides and precipitated with these chemicals. This F species has little 241 biological effectiveness (Xie et al. 1999; Berger et al. 2016). As shown in Table 1, the $F_{\text {fm }}$ content 242 in the loess is rather low, accounts for $0.2-1.1 \%$ of $\mathrm{F}_{\mathrm{tf}}$. Also, the LC profile in the north contains the 
least $\mathrm{F}_{\mathrm{fm}}$, with an average content of $1.95 \mathrm{mg} \mathrm{kg}^{-1}$ representing $0.4 \%$ of $\mathrm{F}_{\mathrm{tf}}$. In the other three profiles in the south, the content of $\mathrm{F}_{\mathrm{fm}}$ falls between 3.17 and $4.10 \mathrm{mg} \mathrm{kg}^{-1}$ on average, representing 0.5$0.7 \%$ of $\mathrm{F}_{\mathrm{tf}}$. Overall concentrations of $\mathrm{F}_{\mathrm{fm}}$ are similar in the three profiles, with that in the BLY profile in the south-central part being the greatest (Fig 2). The $\mathrm{pH}$ condition may be responsible for the relatively small proportion of $\mathrm{F}_{\mathrm{fm}}$ in loess. The loess is under alkline condition (Table 1), whereas secondary $\mathrm{Fe} / \mathrm{Mn}$ oxyhydroxides was considered to adsorb $\mathrm{F}$ in soils preferentially under neutral to acidic conditions (Loganathan et al. 2006; Borgnino et al. 2013; Berger et al. 2016).

Fluorine bound to organics $\left(\mathrm{F}_{\mathrm{or}}\right)$

Humic substances and organic acids widely distributed in soils are responsible for fluorine capture through complexing actions with fluorine bound to produced organics (Xie et al. 1999). The concentrations of $F_{\text {or }}$ in all the samples fluctuate in a relatively wide range from 0.92 to $42.50 \mathrm{mg}$ $\mathrm{kg}^{-1}$ (Table 1). The samples with relatively high content of $\mathrm{F}_{\text {or }}$ almost come from the DL profile in the southeast. The average $F_{\text {or }}$ content in the loess from the profile reaches $15.44 \mathrm{mg} \mathrm{kg}^{-1}$ accounting for $2.5 \%$ of $\mathrm{F}_{\mathrm{tf}}$, with 7.28 and $42.5 \mathrm{mg} \mathrm{kg}^{-1}$ being the minimum and maximum, respectively. The other three profiles have similar levels in $\mathrm{F}_{\text {or }}$ content accounting for less than $1 \%$ of $\mathrm{F}_{\mathrm{tf}}$, which is much lower than the DL profile (Fig 2). Scavenging of $\mathrm{F}^{-}$by organic matter is reportedly most effective below $\mathrm{pH}=6.5$ (Berger et al. 2016). Therefore, it is no surprise that there is relatively low percentage of $\mathrm{F}_{\text {or }}$ in the alkline loess while its proportion in acid soils in southwestern China is much higher (Zhang 2007).

Residual fluorine $\left(\mathrm{F}_{\mathrm{re}}\right)$

Apart from the aforementioned fluorine species, there is residual fluorine existing in mineral lattice in soils, which is unextractable. $F_{\mathrm{re}}$ is considered unavailable to biological activities (Xie et al. 1999; Yi et al. 2013). It takes the overwhelming majority of $F_{t f}$ in all the loess samples, ranging from 461.45 to $789.72 \mathrm{mg} \mathrm{kg}^{-1}$ (Fig 2). Its proportion in $\mathrm{F}_{\mathrm{tf}}$ is between $80.9 \%$ and $97.8 \%$, with $93.6 \%$ on average (Table 1). The DL profile has an average proportion of $89.8 \%$, which is the smallest in the four profiles. It indicates that the extractable $\mathrm{F}$ in the profile is most enriched. In the other three profiles the average proportion of the $\mathrm{F}_{\mathrm{re}}$ is around $95 \%$. higher than that of the other $\mathrm{F}$ species. Then the $\mathrm{F}_{\mathrm{ws}}$ or the $\mathrm{F}_{\mathrm{ex}}$ is the second in amount or percentage. 
In the three profiles in the south, the overall content of $F_{w s}$ is higher than that of $F_{e x}$, whereas it is the contrary in the LC profile in the north with more $F_{\mathrm{ex}} . \mathrm{F}_{\mathrm{fm}}$ occurs in the least amount except in the BLY profile. All in all, the order of the five-fluorine species, from the largest to the smallest, is that $\mathrm{F}_{\mathrm{re}}>\mathrm{F}_{\mathrm{ws}}\left(\mathrm{F}_{\mathrm{ex}}\right)>\mathrm{F}_{\mathrm{ex}}\left(\mathrm{F}_{\mathrm{ws}}\right)>\mathrm{F}_{\mathrm{or}}\left(\mathrm{F}_{\mathrm{fm}}\right)>\mathrm{F}_{\mathrm{fm}}\left(\mathrm{F}_{\mathrm{or}}\right)$ if arranged according to overall content of each species in the four profiles.

The correlation between the different $\mathrm{F}$ species is also studied (Table 2). As the $\mathrm{F}_{\text {re }}$ represents most of the $\mathrm{F}_{\mathrm{tf}}$, its content has a strong positive correlation with that of the $\mathrm{F}_{\mathrm{tf}}$. The $\mathrm{F}_{\mathrm{ws}}$ correlates strongly with both the $F_{t f}$ and the $F_{\text {or }}$. The notable correlation between the $F_{w s}$ and the $F_{t f}$ in loess results from the high $\mathrm{F}_{\mathrm{ws}}$ proportion next to the $\mathrm{F}_{\mathrm{re}}$ in most loess samples. This relationship between them was also found in other studies on F speciation in soils (Zhang 2007; D'Alessandro et al. 2008). And the $F_{w s}$ and the $F_{\text {or }}$ correlates significantly, which was also found in a previous study (Yi et al. 2013). Although the content of the $F_{f m}$ is small, it has positive relationships with the $F_{t f}, F_{w s}, F_{r e}$, and $F_{o r}$. Besides that, there is also a strong correlation between the content of the $F_{e x}$ and the $F_{o r}$. A mechanism explanation can be given for the positive correlation between $F_{\text {or }}$ and either $F_{e x}$ or $F_{f m}$. Multiple functional groups of humic substances matter in soils can bind cations (including $\mathrm{Ca}, \mathrm{Fe}$ and $\mathrm{Al}$ ), which in turn provide adsorption sites for $\mathrm{F}^{-}$while there is already $\mathrm{F}^{-}$absorbed by the organic matter (Murray, 1983; Berger et al. 2016).

\section{Table 2}

\section{Quality assessment of fluorine in loess}

Since $\mathrm{pH}$ of all the loess samples is alkline, $\mathrm{F}_{\mathrm{ws}}$ concentrations in loess samples were adopted as the $C_{i}$ in formula (1) to assess health quality of the loess. As mentioned above, $0.5 \mathrm{mg} \mathrm{kg}^{-1}$ and $5.0 \mathrm{mg}$ $\mathrm{kg}^{-1}$ were assigned to $S_{i 1}$ and $S_{i 2}$ in formula (1), respectively. Results show that 56 loess samples were evaluated as soil with excessive F, accounting for $93 \%$ of all the samples. Only 4 samples belong to soil with normal F. No sample is classed as soil deficient in F. As a whole, the loess in this study can be assessed as inferior health quality as far as $\mathrm{F}$ is concerned. $P_{i}$ range of the four profiles show that health quality of F for the loess in the north of SLP is relatively better than that in the south (Table 1). Moreover, the loess in the southeast of the SLP has the most inferior health quality of $\mathrm{F}$ as it contains the highest $\mathrm{F}_{\mathrm{ws}}$ content and has the greatest $P_{i}$ range.

\section{Exposure assessments}


Since $\mathrm{F}$ is not readily taken up by plants, the $\mathrm{F}$ intake of grazing sheep largely comes from soil ingestion, especially during the winter months (Grace et al. 2003). It was found that a safe threshold dietary concentration for $\mathrm{F}$ should be satisfied before the long-term $\mathrm{F}$ intake results in chronic fluorosis. And grazing animals might be at risk if they ingest high-F soil with high rates (Grace et al. 2003; Loganathan et al. 2006). In Fig 3, DF range exposed to the loess of each profile for grazing animals has been illustrated with10-25\% of DM intake. DF for grazing animals varies from 46-197 $\mathrm{mg} \mathrm{kg}^{-1} \mathrm{DM}$ if the loess in this study is ingested (Fig 3). Loess in the north, which has the relatively low $\mathrm{F}_{\mathrm{tf}}$ content, is generally safe for grazing animals as shown by the DF range from the LC profile with most values except two ones are under the upper limits. As a result of the high $\mathrm{F}_{\mathrm{tf}}$ content, the loess in the southwest might pose a much greater risk to grazing animals in terms of $\mathrm{F}$ exposure. It is indicated by the DF range from the BJ profile, in which most values significantly surpass the acceptable limits. Although the $\mathrm{F}_{\mathrm{tf}}$ content of the loess in the south-central and southeastern SLP is also relatively high, it is generally tolerable for grazing animals if the loess ingested by them. This is because DF range assessed from F concentrations in the two profiles, the BLY and the DL profile, mostly falls below or close to the limits with only a few samples having values far above the limits (Fig 3).

Children's exposure to F via ingestion of loess was assessed according to formula (4). The calculated DI values for all the samples are between 0.004 and $0.123 \mu \mathrm{g} \mathrm{kg}^{-1} \mathrm{day}^{-1}$. It shows that the exposure is far below $58 \mu \mathrm{g} \mathrm{kg}^{-1} \mathrm{day}^{-1}$, the upper limited value stipulated by Chinese Nutrition Society (2014). Given the assessed exposure values are two and four orders of magnitude less than the acceptable limit, there is no concern for the children's exposure to F in the loess via ingestion in the present condition. However, there were reports on surge in $\mathrm{F}$ concentration in environment caused by application of high-fluorine fertilizers and the resulted adverse impacts on animals or humans (Loganathan et al. 2008; Yu et al. 2020). If application of F-containing fertilizers leads to substantial elevation of $\mathrm{F}$ content in some loess strata, it is possible that the exposure to $\mathrm{F}$ may also increase greatly. Therefore, the southwest and the southeast SLP might more potentially be F-exposure risk prone regions if the original high background $\mathrm{F}_{\mathrm{ws}}$ in the loess is coupled with a considerable addition 
334 High-fluoride shallow groundwater is widely distributed in the SLP. The fluoride distribution in 335 groundwater in the SLP, especially in the southern part, Guanzhong Basin, has been studied by some researchers (Zhu et al. 2008; Deng et al. 2009a, b). According to the results, eastern part of the basin, in which the DL profile in this study lies, is a region with the highest occurrence of highfluoride groundwater. Groundwater around the DL profile generally contains F concentration from 2.0 to $4 \mathrm{mg} / \mathrm{L}$. From the east to the west of the basin, there is an overall trend that the fluoride content in groundwater decreases. In the central part of the basin where the BLY profile is included, the fluoride content in groundwater is overall less than that in the east. To the west of the basin, in which the BJ profile is located, the fluoride concentration in groundwater decreases to the overall lowest level of the basin with almost all groundwater samples having F content less than $1.0 \mathrm{mg} / \mathrm{L}$. In the northern SLP where the LC profile lies, the fluoride content in groundwater is rather low according to unpublished local hydrogeochemical data. Three groundwater samples collected around the LC profile have F concentrations of $0.45,0.52$, and $0.64 \mathrm{mg} / \mathrm{L}$, respectively. With regards to the genesis of high-fluoride groundwater in the southeast SLP, interaction between groundwater and contacting rocks and soils is a critical formation mechanism and fluoride in groundwater primarily origins from F in rocks and soils (Zhu et al. 2008; Li et al. 2014; Xiao et al. 2015; Li et al. 2019; Xu et al. 2019). In the central basin, namely the south-central SLP, however, besides the geogenic origin, fluoride enrichment in groundwater may be partially attributed to the local highfluoride thermal water, which rises along faults and mixes into groundwater (Deng et al. 2009a, b). Loess is an important groundwater medium in the SLP and comprises such fluorine-containing minerals. Therefore, F in loess might be closely associated with the genesis of local high-fluoride groundwater (Zhu et al. 2008; Li et al. 2019). Combined with the F distribution characteristics in the groundwater, the above F speciation may help to clarify further the relationship. Here discussed is the F speciation in loess and fluoride content in groundwater in the southeast, southwest and north

358 SLP without including that in the south-central SLP as the complication of groundwater fluoride sources there is concerned. Loganathan et al. (2006) has ever pointed out that F-contamination risk to groundwater depended on the soluble soil $\mathrm{F}$ concentrations. It means that $\mathrm{F}_{\mathrm{ws}}$ rather than $\mathrm{F}_{\mathrm{tf}}$ in loess plays an important role in contributing $\mathrm{F}$ to groundwater. It is proved to be true in this study. The loess from the north has both the lowest $\mathrm{F}_{\mathrm{tf}}$ and $\mathrm{F}_{\mathrm{ws}}$ content while the groundwater has relatively 
the lowest fluoride content. But in the southwest of the SLP, the loess has lower $F_{w s}$ content and higher $\mathrm{F}_{\mathrm{tf}}$ content than in the southeast, whereas there is much lower fluoride concentration in groundwater than that in the southeast (Deng et al. 2009b). Furthermore, as a matter of fact, the difference between the $F_{w s}$ content for each profile is not so significant compared to that between the total content of extractable $F$, which is the sum of $F_{w s}, F_{e x}, F_{f m}$ and $F_{o r}$ concentrations (Fig. 4). For example, the difference value is $8 \mathrm{mg} \mathrm{kg}^{-1}$ between the average $\mathrm{F}_{\mathrm{ws}}$ concentrations of the $\mathrm{BJ}$ and the DL profile, whereas that is $22.4 \mathrm{mg} \mathrm{kg}^{-1}$ between the average extractable F concentrations of the two profiles. And the corresponding difference values between the LC and the BJ profile are 10.0 and $17.2 \mathrm{mg} / \mathrm{L}$, respectively. It may suggest that extractable $\mathrm{F}$ in loess, not just $\mathrm{F}_{\mathrm{ws}}$, is related to the genesis of groundwater fluoride in the loess area. Although rather low is the respective content of the other three types of extractable fluorine species except $\mathrm{F}_{\mathrm{ws}}$, the sum of them cannot be negligible for contribution to groundwater fluoride enrichment.

Fig 4

\section{Conclusions}

In the SLP, there is distributed widely typical loess, which is enriched in F. To have a better understanding of F geochemistry in loess, the F speciation of the loess in the SLP was studied. On the basis of that, animal and human exposures to loess $\mathrm{F}$ were assessed. And implication of the $\mathrm{F}$ speciation of loess on the risk to fluoride enrichment in groundwater was also discussed. The following are the major findings:

1) Loess has high $\mathrm{F}_{\mathrm{tf}}$ content in a range of $461.45-789.72 \mathrm{mg} \mathrm{kg}^{-1}$, with higher content in the loess from the south SLP than the north SLP. Of the F species in loess, the unextractable $F_{\text {re }}$ accounts for most percentage of $\mathrm{F}_{\text {tf }}$ from 80.9 to $97.8 \%$. Of the four extractable fluorine species including $F_{w s}, F_{e x}, F_{\text {fm }}$ and $F_{\text {or }}, F_{w s}$ is the most important species in loess as its content in most loess samples is the highest. Except loess in the north SLP that has relatively low $\mathrm{F}_{\mathrm{tf}}$ content, the loess in the south has much lower content of the other three extractable fluorine species, compared to that of $F_{w s}$. The average $F_{w s}$ content in the loess greatly surpasses that in soils in Chinese endemic fluorosis prone areas, with an average of 6.14 for all samples and a maximum of 38.97 mg kg-1 occurring in loess in the southeast SLP. Although $F_{w s}$ in loess overall has a significant correlation with the $F_{t f}$, not all loess samples with high $F_{t f}$ content necessarily have high $F_{w s}$ content as shown in the comparison between the BJ profile in the southwest and the DL profile 
in the southeast. Loess in the southeast has the highest $F_{w s}$ content in spite of its second highest $\mathrm{F}_{\mathrm{tf}}$ content.

2) As loess has alkline $\mathrm{pH}, \mathrm{F}_{\mathrm{ws}}$ concentrations were the adopted in the quality assessment of

Acknowledgments: The research is financially supported by the Natural Science Basic Research

3) According to the characteristics of F species in the loess, the exposure to the loess F via ingestion have been assessed for animals and humans, respectively. The exposure to grazing animals was estimated based on $\mathrm{F}_{\mathrm{ff}}$ content in loess. The assessment results show that $\mathrm{F}$ in the loess in the southwest SLP might pose a much greater risk to grazing animals than in other part of the SLP as the loess contains more $\mathrm{F}_{\mathrm{tf}} . \mathrm{F}_{\mathrm{ws}}$ content in loess is the basis of exposure assessment for humans. Only children's exposure to F via ingestion of loess was assessed for their special modes of activity different from adults. Fortunately, there is no concern for the children's exposure to $\mathrm{F}$ in the loess via ingestion in the present condition.

4) With the F speciation in loess in the SLP and distribution of local high-fluoride groundwater, it can be found that the higher the content of $\mathrm{F}_{\mathrm{ws}}$ in loess, the higher fluoride content in local groundwater. It proves other researcher's viewpoints on dependence of $\mathrm{F}^{-}$contamination in groundwater on soluble $\mathrm{F}$ in soils. In addition, the other three types of $\mathrm{F}$ species including $\mathrm{F}_{\mathrm{ex}}$, $F_{\text {fm }}$ and $F_{o r}$, although their respective concentration is quite low similar to $F_{w s}$, also contribute to F enrichment in the groundwater in the SLP. It may indicate that extractable F species, not just $\mathrm{F}_{\mathrm{ws}}$, may be responsible for the genesis of groundwater fluoride in the loess area.

in Shaanxi Province of China (Program No. 2019JM-512) and the Open Foundations of State Key Laboratory of Loess and Quaternary Geology, Institute of Earth Environment, Chinese Academy of Sciences (SKLLQG1605). The authors are grateful to Professor Liu Xiuhua, Chang'an University for her help in field sampling. 
Author contributions: The study idea and methodology were developed by Lin Deng. Lin Deng, Jiangxia Wang and Xiaoting Yang were involved in the field sampling and laboratory analysis. Bin $\mathrm{Xu}$ and Anyan Hu participated in the laboratory analysis and data processing. The first draft of the manuscript was written by Lin Deng. Jiangxia Wang and Bin Xu helped in editing the first versions of the manuscript. Previous versions of the manuscript were discussed by all authors.

Consent to participate and publish: All authors participating in this study agreed to publish.

Data availability statement: Raw data may be provided upon reasonable request.

\section{Compliance with ethical standards and conflict of interest:}

The authors claim that they have no relevant competing financial or non-financial interests that would have appeared to influence the work in this paper. And there is no research involving human and animal participants in this study. Besides that, such infractions including plagiarism, data fabrication and/or falsification, double publication and/or submission do not exist at all in this paper.

\section{References}

Andrade R (2012) Integrated use of geophysical, hydrological and geographic information system (GIS) methods in enhancing the groundwater quality in a fluoride-endemic terrain (Andhra Pradesh, India). Hydrogeol J 20 (8):1589-1597. https://doi.org/10.1007/s10040-012-0898-3

Arveti N, Sarma MRS, Aitkenhead-Peterson JA, Sunil K (2011) Fluoride incidence in groundwater: a case study from Talupula, Andhra Pradesh, India. Environ Monit Assess 172 (1-4):427-443. https://doi.org/10.1007/s10661-010-1345-3

Ayenew T (2008) The distribution and hydrogeological controls of fluoride in the groundwater of central Ethiopian rift and adjacent highlands. Environ Geol 54 (6):1313-1324. https://doi.org/10.1007/s00254-007-0914-4

Berger T, Yu C, Drake H, Peltola P, Svensson D, Åström M E (2016) Fluorine geochemistry of quaternary deposits in a nemo-boreal catchment with elevated dissolved fluoride in surface waters and groundwater. J Geochem Explor 170:148-156. https://doi.org/10.1016/j.gexplo.2016.09.003

Bierkens J, Van Holderbeke M, Cornelis C, Torfs R (2011) Exposure through soil and dust ingestion. 
In: Swartjes F (ed) Dealing with contaminated sites. Springer, Dordrecht, pp 261-286. https://doi.org/10.1007/978-90-481-9757-6_6

Borgnino L, Garcia MG, Bia G, Stupar YV, Le Coustumer P, Depetris PJ (2013) Mechanisms of fluoride release in sediments of Argentina's central region. Sci Total Environ 443:245-255. https://doi.org/10.1016/j.scito tenv.2012.10.093

Brindha K, Jagadeshan G, Kalpana L, Elango L (2016) Fluoride in weathered rock aquifers of southern India: managed aquifer recharge for mitigation. Environ Sci Pollut Res 23:8302-8316. https://doi.org/10.1007/s11356-016-6069-7

Chinese Nutrition Society (2014) Chinese Dietary Reference Intakes (DRIs), 2013 edition. Science Press, Beijing

CNEMC (1990) China National Environmental Monitoring Center. The soil background values of China. China Environmental Science Press, Beijing. (in Chinese)

Cronin SJ, Manoharan V, Hedley MJ, Loganathan P (2000) Fluoride: a review of its fate, bioavailability, and risks of fluorosis ingrazed-pasture systems in New Zealand. New Zealand Journal of Agricultural Research 43:295-321. https://doi.org/10.1080/00288233.2000.9513430

Currell M, Cartwright I, Raveggi M, Han D (2011) Controls on elevated fluoride and arsenic concentrations in groundwater from the Yuncheng Basin, China. Appl Geochem 26(4):540-552. https://doi.org/10.1016/j.apgeochem.2011.01.012

D'Alessandro W, Bellomo S, Parello F (2008) Fluorine speciation in topsoils of three active volcanoes of Sicily (Italy). Environ Geol 56:413-423. https://doi.org/10.1007/s00254-007-11797

Davison LH, Weinstein LH (2006) Some problems relating to fluorides in the environment: effects on plants and animals. Chap. 8 In: In: Tressaud A (ed) Fluorine and the environment, atmospheric chemistry, emissions, \& lithosphere, vol. 1. Elsevier, Amsterdam, pp 251-298

Deng L, Wang W, Tian H, Yang X (2009a) Chemical Characteristics of Shallow High-Fluoride Groundwater in Guanzhong Basin, China. 3rd International Conference on Bioinformatics and Biomedical Engineering. https://doi.org/10.1109/icbbe.2009.5162496

Deng L, Wang W, Yang X (2009b) Characteristics of spatial variation and distribution of fluoride content of groundwater in Guanzhong Basin. China Rural Water and Hydropower 318:77-80. (in Chinese) 
Egeghy PP, Sheldon LS, Fortmann RC, Stout DM II, Tulve NS, Cohen Hubal E, Melnyk LJ, Morgan M, Jones PA, Whitaker DA, Croghan CW, Coan A (2007) Important exposure factors for children. An analysis of laboratory and observational field data characterizing cumulative exposure to pesticides; EPA 600/R-07/013

Fewtrell L, Smith S, Kay D, Bartram J (2006) An attempt to estimate the global burden of disease due to fluoride in drinking water. $\mathrm{J}$ Water Health 4:533-542. https://doi.org/10.2166/wh.2006.045

Fuge R (2019) Fluorine in the environment, a review of its sources and geochemistry. Appl Geochem 100:393-406. https://doi.org/10.1016/j.apgeochem.2018.12.016

Gao H, Cheng J, Ma C, Chen F, Liu S, Li J. Zhang X, Zhao J, Dai G, Yu, Ju F, Wei J (1990) The relation study between soil fluoride and local fluoride epidemic. China Endemic Journal 9(1):3639. (in Chinese)

Grace ND, Loganathan P, Hedley MJ, Wallace GC (2003) Ingestion of soil fluorine: its impact on the fluorine metabolism and status of grazing young sheep. New Zealand Journal of Agricultural Research 46:279-286. https://doi.org/10.1080/00288233.2003.9513555

Jayawardana DT, Pitawala HMTGA, Ishiga H (2012). Geochemical assessment of soils in districts of fluoride-rich and fluoride-poor groundwater, north-central Sri Lanka. J Geochem Explor 114:118-125. https://doi.org/10.1016/j.gexplo.2012.01.004

Jha SK, Mishra VK, Sharma DK, Damodaran T (2011) Fluoride in the environment and its metabolism in humans. In: Whitacre DM (ed) Reviews in environmental contamination and toxicology, vol 211. Springer, New York, pp 121-142

Kabata-Pendias A, Pendias H (2001) Trace elements in soil and plants, 3rd edn. CRC press, Boca Raton, pp. 403

Li J, Xie Z, Xu J, Wu W (2005). Preliminary study on guideline on soil health quality index of fluorine and method of its evaluation in China. Journal of Zhejiang University (Agric And life Sci) 31(5):593-597. (in Chinese)

Li P, He X, Li Y, Xiang G (2019) Occurrence and Health Implication of Fluoride in Groundwater of Loess Aquifer in the Chinese Loess Plateau: A Case Study of Tongchuan, Northwest China. Exposure and Health 11:95-107. https://doi.org/10.1007/s12403-018-0278-x

Li P, Qian H, Wu J, Chen J, Zhang Y, Zhang H (2014) Occurrence and hydrochemistry of fluoride 

https://doi.org/10.1007/s12665-013-2691-6

Liu R, Zhu H, Kang M, Jiao J, Yang B, Qiao G, Zhao A, Liu J (2009) Hydrogeochemistry of the

Liu T, Zhang S, Han J (1986) Stratigraphy and paleoenvironmental changes in the loess of central China. Quaternary Science Reviews 5:489-495. https://doi.org/10.1016/0277-3791(86)90215-5

Wu W, Xie Z, Xu J, Hong Z, Liu C (2002) Characteristics of forms of fluorine in soils and influential

Loganathan P, Gray CW, Hedley MJ, Roberts AHC (2006) Total and soluble fluorine concentrations in relation to properties of soils in New Zealand. Eur J Soil Sci 57:411-421. https://doi.org/10.1111/j.1365-2389.2005.00751.x

Loganathan P, Hedley MJ, Grace ND (2008) Pasture soils contaminated with fertilizer-derived cadmium and fluorine: livestock effects. In: Whitacre DM (ed) Reviews of environmental contamination and toxicology, vol 192. Springer, New York, pp 29-66. https://doi.org/10.1007/978-0-387-71724-1_2

McLaughlin MJ, Stevens DP, Keerthisinghe DG, Cayley JWD, Ridley AM (2001) Contamination of soil with fluoride by long-term application of superphosphates to pastures and risk to grazing animals. Australian Journal of Soil Research 39:627-640. https://doi.org/10.1071/sr00036

MEE (2018) The Ministry of Ecology and Environment, People's Republic of China. Environmental quality standard for agricultural land soils, from https://www.mee.gov.cn

Murray F (1983) Fluoride retention by sandy soils. Water Air Soil Pollut 20:361-367. https://doi.org/10.1007/BF00208510

Wang C, Yang Z, Chen L, Yuan X, Liao Q, Ji J (2012) The transfer of fluorine in the soil-wheat system and the principal source of fluorine in wheat under actual field conditions. Field Crop Res 137:163-169. https://doi.org/10.1016/j.fcr.2012.08.001

WHO (2017) Guidelines for drinking water quality: fourth edition incorporating the first addendum. World Health Organization, Geneva factors. Environmental Science 23(2):104-108. (in Chinese)

Xiao J, Jin Z, Zhang F (2015) Geochemical controls on fluoride concentrations in natural waters 
from the middle Loess Plateau, China. J Geochem Explor 159:252-261. https ://doi.org/10.1016/j. gexpl o.2015.09.018

Xie Z, Wu W, Xu J (1999) Translocation and transformation of fluorides in the environment and their biological effects. Advances in Environmental Science 7(2):40-53 (in Chinese).

Xu B, Zhang Y, Wang J (2019) Hydrogeochemistry and human health risks of groundwater fluoride in Jinhuiqu irrigation district of Wei river basin, China. Hum Ecol Risk Assess 25(1-2):1-20. https ://doi.org/10.1080/10807039.2018.15309

Yi C, Wang B, Jin M (2013) Fluorine speciation and its distribution characteristics in selected agriculture soils of North China Plain. Evinronmental Science 34(8):3195-3204 (in Chinese).

Yu Y, Yang J (2020) Health risk assessment of fluorine in fertilizers from a fluorine contaminated region based on the oral bioaccessibility determined by Biomimetic Whole Digestion-Plasma in-vitro Method (BWDPM). Journal of Hazardous Materials 383:121124. https ://doi.org/10.1016/j.jhazmat.2019.121124

Zhang Y (2007) The distribution of fluorine in soil from epidemic fluorosis areas in Guizhou Province. Journal of Guizhou Normal University (Natural Sciences) 25(4):41-43, 47. (in Chinese)

Zhu C, Bai G, Liu X, Li Y (2006) Screening high-fuoride and higharsenic drinking waters and surveying endemic fuorosis and arsenism in Shaanxi province in western China. Water Res 40(16):3015-3022. https://doi.org/10.1016/j.watres.2006.06.026

Zhu H, Yang B, Zhao A, Ke H, Liu R, Qiao G (2008). Distribution characteristics and origin of highfluorine groundwater at Dali, Shaanxi, China. Geological Bulletin of China 27(8):1192-1195. (in Chinese)

\section{Figure captions}

Figure 1 The study area and location of sampling profiles

Figure 2 Distribution of $\mathrm{F}$ speciation in the profiles 
572 Figure 3 DF (daily exposure to soil F) range exposed to each loess profile for grazing animals

573 with $10-25 \%$ of DM (daily dry matter) intake

574 Figure 4 Comparison between the content of $F_{w s}$ and all extractable $F$ for the profiles 
Table 1 Statistics of fluorine speciation, $\mathrm{pH}$ and $\mathrm{Pi}$ values of loess samples from the profiles

\begin{tabular}{|c|c|c|c|c|c|c|c|c|c|c|c|c|c|c|c|c|c|c|c|}
\hline & ${ }^{\mathrm{a}}$ Concentration & & $\mathrm{F}_{\mathrm{ws}}$ & & & $\mathrm{F}_{\mathrm{ex}}$ & & & $\mathrm{F}_{\mathrm{fm}}$ & & & $\mathrm{F}_{\text {or }}$ & & & $\mathrm{F}_{\mathrm{re}}$ & & & $\mathrm{F}_{\mathrm{tf}}$ & \\
\hline profile & $\begin{array}{c}\text { and } \\
\text { percentages }\end{array}$ & Max. & Min. & Mean & Max. & Min. & Mean & Max. & Min. & Mean & Max. & Min. & Mean & Max. & Min. & Mean & Max. & Min. & Mean \\
\hline $\begin{array}{c}\text { LC } \\
{ }^{\mathrm{b}} \mathrm{pH}: 8.73-10.19\end{array}$ & $\begin{array}{l}\text { Concentration } \\
\left(\mathrm{mg} \mathrm{kg}^{-1}\right)\end{array}$ & 11.24 & 1. 40 & 6. 14 & 34.27 & 1. 37 & 9.21 & 3. 07 & 1.02 & 1.95 & 8.46 & 2.25 & 4.27 & 618.02 & 450.59 & 518.86 & 642.13 & 461.45 & 540.44 \\
\hline $\begin{array}{c}{ }^{c} 1.23 \quad\left(0.28^{-}\right. \\
2.25)\end{array}$ & $\begin{array}{c}\text { Percentages } \\
(\%)\end{array}$ & 1.8 & 0.3 & 1.1 & 6.9 & 0.3 & 1.8 & 0.5 & 0.2 & 0.4 & 1.6 & 0.4 & 0.8 & 97.8 & 91.2 & 96 & - & - & - \\
\hline $\begin{array}{c}\text { BJ } \\
{ }^{\mathrm{b}} \mathrm{pH}: 8.50-10.94\end{array}$ & $\begin{array}{c}\text { Concentration } \\
\left(\mathrm{mg} \mathrm{kg}^{-1}\right)\end{array}$ & 31.98 & 5.32 & 16. 16 & 64. 20 & 3. 09 & 13.63 & 4.93 & 1.59 & 3.17 & 13. 02 & 2.43 & 5.82 & 761.13 & 458.04 & 604.07 & 789. 72 & 518.70 & 642.84 \\
\hline $\begin{array}{c}{ }^{\circ} 3.23\left(1.06^{-}\right. \\
6,40)\end{array}$ & $\begin{array}{c}\text { Percentages } \\
(\%)\end{array}$ & 4.8 & 1.0 & 2.4 & 12 & 0.5 & 2.2 & 0.8 & 0.3 & 0.5 & 1.9 & 0.3 & 0.9 & 96.6 & 85.3 & 93.9 & - & - & - \\
\hline $\begin{array}{c}\text { BLY } \\
{ }_{\mathrm{p}}^{\mathrm{pH}:}: 7.98^{-9.03}\end{array}$ & $\begin{array}{c}\text { Concentration } \\
\left(\mathrm{mg} \mathrm{kg}^{-1}\right)\end{array}$ & 14. 46 & 6.47 & 10.09 & 15.65 & 1.31 & 5.37 & 7. 11 & 1.58 & 4.10 & 6.44 & 0.92 & 2.98 & 733.17 & 476.83 & 565.25 & 761.90 & 499. 50 & 587.79 \\
\hline $\begin{array}{c}{ }^{\mathrm{c}} 2.02(1.29- \\
2.89)\end{array}$ & $\begin{array}{c}\text { Percentages } \\
(\%)\end{array}$ & 2.9 & 0.9 & 1.8 & 2.8 & 0.2 & 0.9 & 1.0 & 0.3 & 0.7 & 1.0 & 0.2 & 0.5 & 97.4 & 94.5 & 96.1 & - & - & - \\
\hline $\begin{array}{c}\text { DL } \\
{ }^{\mathrm{b}} \mathrm{pH}: 8.54-10.76\end{array}$ & $\begin{array}{l}\text { Concentration } \\
\left(\mathrm{mg} \mathrm{kg}^{-1}\right)\end{array}$ & 38.97 & 7.97 & 24.17 & 56.45 & 1.90 & 17.57 & 6.99 & 1.95 & 4.02 & 42.50 & 7. 28 & 15. 44 & 618.60 & 442. 06 & 533.48 & 744. 16 & 501.92 & 594.67 \\
\hline $\begin{array}{c}{ }^{\circ} 4.83(1.59- \\
7.79)\end{array}$ & $\begin{array}{c}\text { Percentages } \\
(\%)\end{array}$ & 6.4 & 1.5 & 4.1 & 10.3 & 0.4 & 2.9 & 1.1 & 0.4 & 0.7 & 5.7 & 1.2 & 2.5 & 93.9 & 80.9 & 89.8 & - & - & - \\
\hline \multirow{2}{*}{$\begin{array}{c}\text { Four } \\
\text { profiles }\end{array}$} & $\begin{array}{c}\text { Concentration } \\
\left(\mathrm{mg} \mathrm{kg}^{-1}\right)\end{array}$ & 38.97 & 1.40 & 15.21 & 64.20 & 1.31 & 11.94 & 7. 11 & 1.02 & 3.43 & 42.50 & 0.92 & 7. 71 & 761.13 & 442.06 & 557.56 & 789. 72 & 461.45 & 595.85 \\
\hline & $\begin{array}{c}\text { Percentages } \\
(\%)\end{array}$ & 6.4 & 0.3 & 2.5 & 12 & 0.2 & 2 & 1.1 & 0.2 & 0.6 & 5.7 & 0.2 & 1.3 & 97.8 & 80.9 & 93.6 & - & - & - \\
\hline
\end{tabular}

a concentrations of different fluorine species and their percentages in total fluorine in loess samples

${ }^{\mathrm{b}} \mathrm{pH}$ range of loess samples from each profile

$c$ the average Pi value of respective profile with the range in the following bracket 
Table 2 Correlation coefficients between different fluorine species

\begin{tabular}{ccccccc}
\hline & $\mathrm{F}_{\text {tf }}$ & $\mathrm{F}_{\mathrm{ws}}$ & $\mathrm{F}_{\mathrm{ex}}$ & $\mathrm{F}_{\mathrm{fm}}$ & $\mathrm{F}_{\text {or }}$ & $\mathrm{F}_{\mathrm{re}}$ \\
\hline $\mathrm{F}_{\text {tf }}$ & 1 & & & & & \\
$\mathrm{~F}_{\mathrm{ws}}$ & $0.374^{* *}$ & 1 & & & & \\
$\mathrm{~F}_{\mathrm{ex}}$ & 0.051 & 0.013 & 1 & & & \\
$\mathrm{~F}_{\mathrm{fm}}$ & $0.397^{* *}$ & $0.313^{*}$ & 0.046 & 1 & 1 & \\
$\mathrm{~F}_{\mathrm{or}}$ & 0.235 & $0.532^{* *}$ & $0.465^{* *}$ & $0.323^{*}$ & 1 & \\
$\mathrm{~F}_{\mathrm{re}}$ & $0.951^{* *}$ & 0.196 & -0.197 & $0.311^{*}$ & -0.025 & 1 \\
\hline
\end{tabular}

**The correlation was significant at the 0.01 level $(n=60)$

* The correlation was significant at the 0.05 level $(n=60)$ 
Figures

\section{Figure 1}

The study area and location of sampling profiles

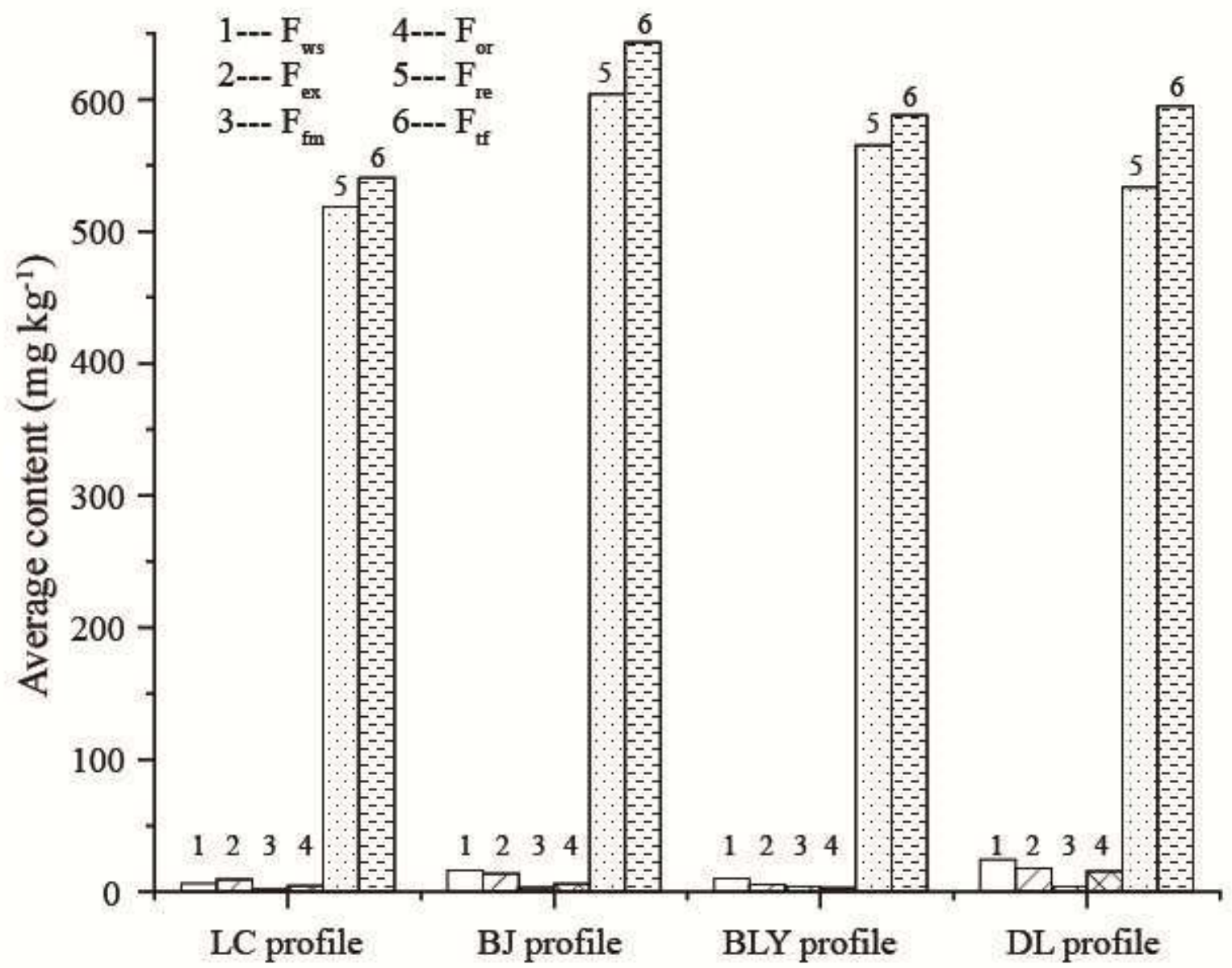

Figure 2

Distribution of $F$ speciation in the profiles 


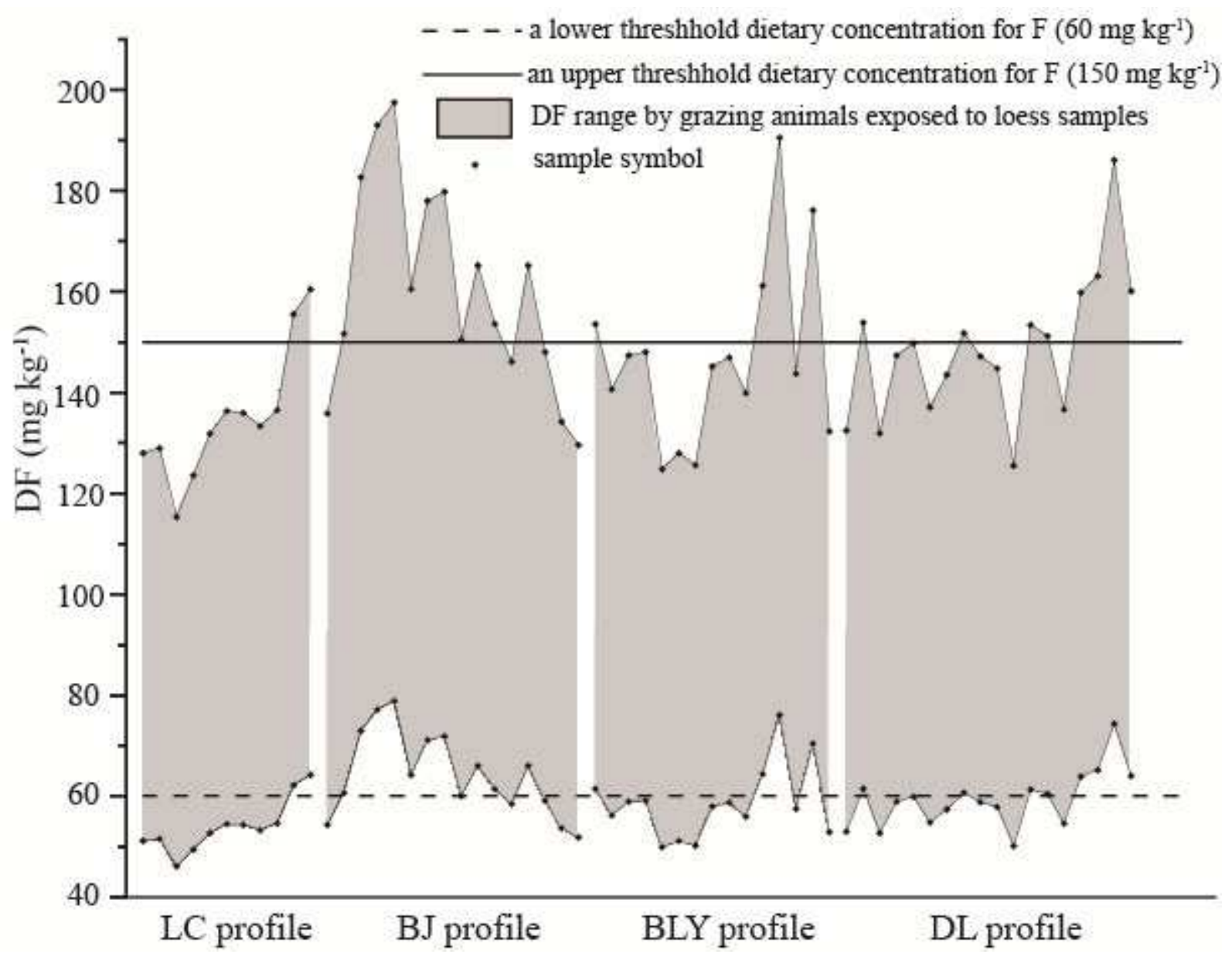

Figure 3

DF (daily exposure to soil F) range exposed to each loess profile for grazing animals with $10-25 \%$ of DM (daily dry matter) intake 


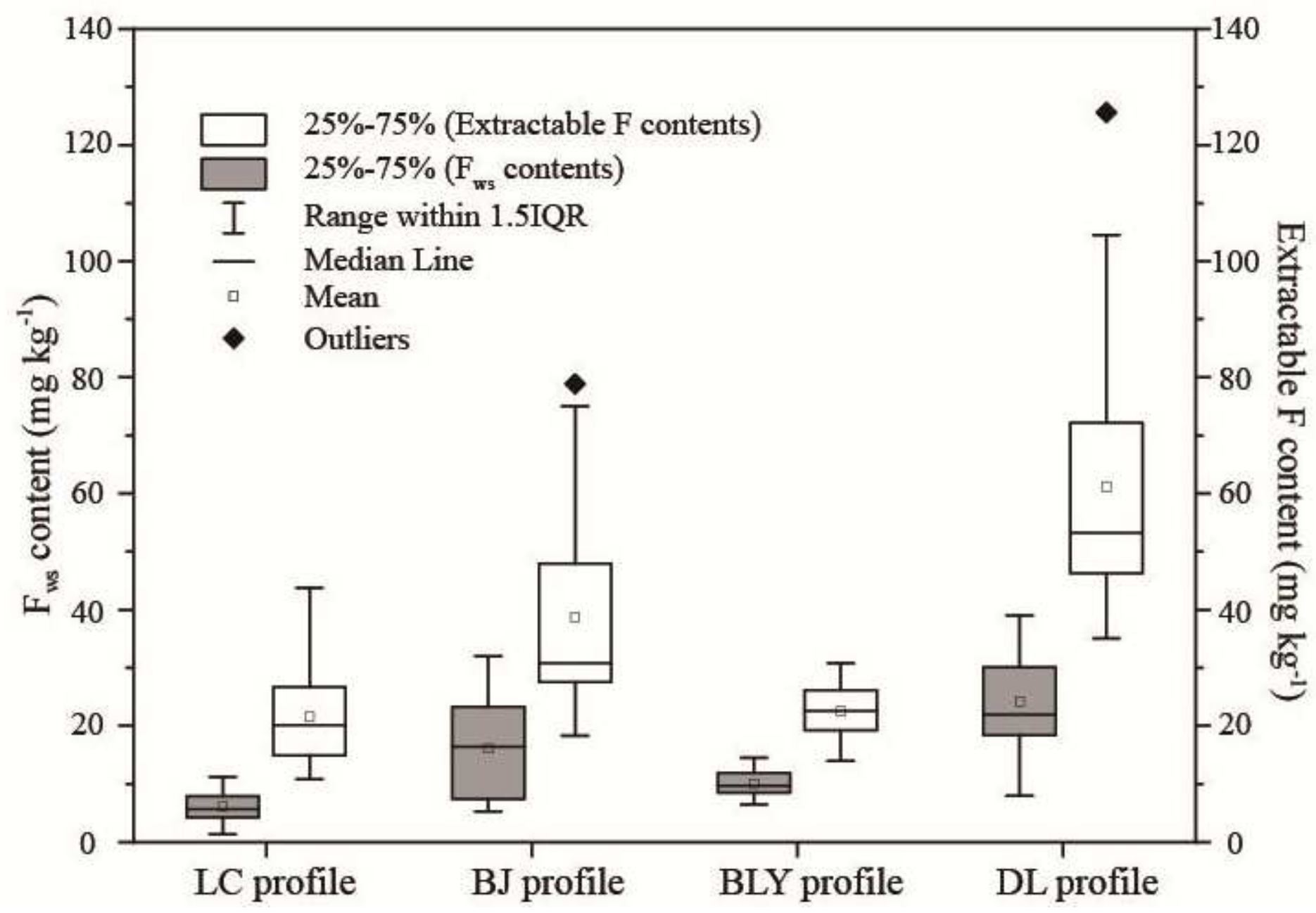

Figure 4

Comparison between the content of Fws and all extractable $F$ for the profiles 